\title{
Bouveret syndrome: When there are no options
}

\author{
Harith Baharith MBBS, Khurram Khan MD FRCPC
}

\section{CASE PRESENTATION}

An 85-year-old female nursing home resident presented with a medical history of dementia, stroke, hypertension, gastroesophageal reflux disease and cholethiasis. The patient was referred because of four episodes of coffee-ground emesis and symptoms of right upper quadrant abdominal pain, with no issues with bowel movements. There was limited other information available due to the underlying history of dementia. The patient's vital signs were stable. Physical examination revealed normal cardiorespiratory parameters. The abdominal examination revealed a tender right upper quadrant, with no palpable mass and the presence of bowel sounds. Laboratory investigations revealed a white blood cell count of $18.4 \times 10^{9} / \mathrm{L}$ (normal $4.0 \times 10^{9} / \mathrm{L}$ to $11.0 \times 10^{9} / \mathrm{L}$ ), alkaline phosphatase level of $131 \mathrm{U} / \mathrm{L}$ (normal $40 \mathrm{U} / \mathrm{L}$ to $120 \mathrm{U} / \mathrm{L}$ ) and gamma-glutamyl transferase level of $116 \mathrm{U} / \mathrm{L}$ (normal $<37 \mathrm{U} / \mathrm{L}$ ). The remaining laboratory investigations were unremarkable. An abdominal $x$-ray revealed a large, rounded, lamellated calcification in the epigastric region measuring approximately $4.5 \mathrm{~cm} \times 3.3 \mathrm{~cm}$ (Figure 1). The patient underwent a computed tomography scan, which revealed gastric outlet obstruction secondary to an impacted gallstone within the duodenum, a cholecystoduodenal fistula and a collpased gallbladder, with thickening of the gallbladder wall and air within the gallbladder (Figure 2). The patient was initially managed with intravenous fluids, nasogastric tube, antiemetics and antibiotics. An urgent endoscopy was arranged by gastroenterology, revealing a

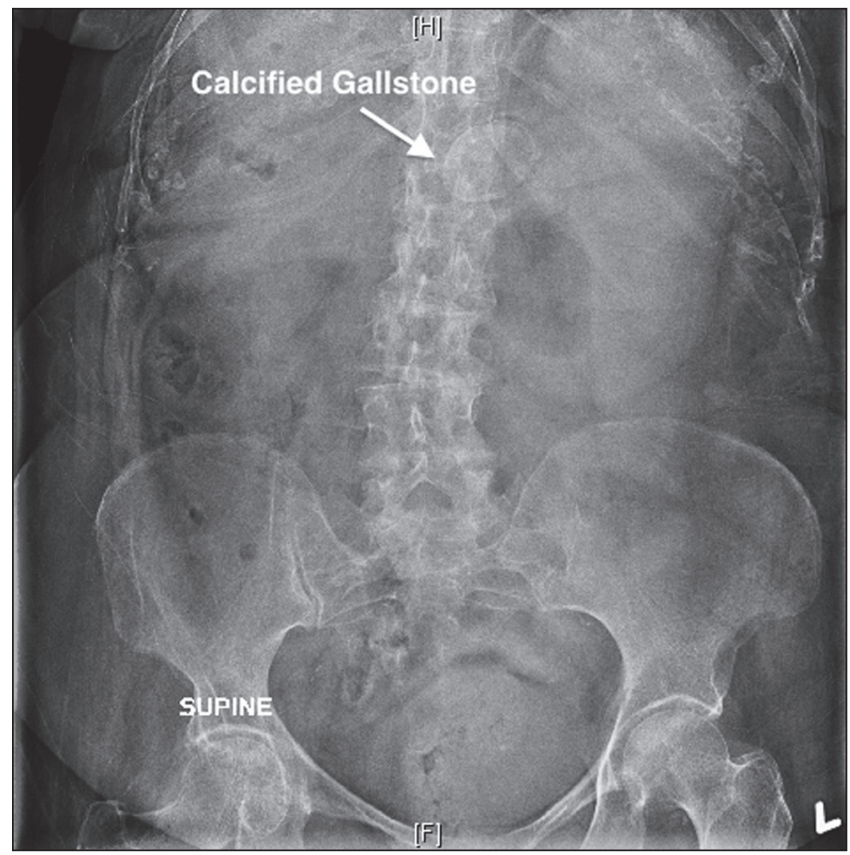

Figure 1) Abdominal x-ray. Ectopic calcified gallstone stone impacted in the duodenal cap (Figure 3). Attempts to push or bypass the stone were unsuccessful, followed by attempts at retrieval with snare, basket, pronged grasper and Roth net, all of which were also unsuccessful. Additional attempts by another gastroenterologist and surgeon using endoscopic therapy to disimpact the stone were unsuccessful. The surgeon then suggested operative management for the patient; however, due to the patient's deteriorating medical condition, the palliative team involved in her care and the family elected to proceed with palliation instead of surgery. After a three-week hospital stay, the patient was transferred to a hospice care facility where she died within one week.

\section{DISCUSSION}

In 1896, the first two cases of gastric outlet obstruction from an impacted gallstone were reported by Leon Bouveret $(1,2)$. Generally, $1 \%$ to $4 \%$ of intestinal obstruction are caused by gallstone ileus and, of these, $1 \%$ to $3 \%$ are caused by Bouveret syndrome $(3,4)$. It is known to occur in elderly women due to the high incidence of gallstones and can cause significant morbidity and mortality, especially in patients with multiple comorbidities (5). To diagnose Bouveret syndrome, the Rigler triad of small-bowel obstruction, pneumobilia and ectopic gallstone is virtually pathognomonic; however, in conventional radiographs, it is present in only $30 \%$ to $35 \%$ of cases and is more readily apparent on computed tomography scan $(2,6,7)$. The pathophysiology of this syndrome stems from increases in intraluminal pressure caused by obstruction, which leads to local ischemia and necrosis, enabling the gallstone to perforate the walls and pass into the intestines (4). Stones $<2.5 \mathrm{~cm}$ in size usually pass into the small bowel while larger gallstones usually become impacted within the gastric outlet (3). Because the syndrome is common in elderly patients with comorbidities and higher perioperative surgical risk, an endoscopic approach is usually the first-line intervention (8). Despite many available endoscopic techniques, including mechanical lithotripsy, net extraction,

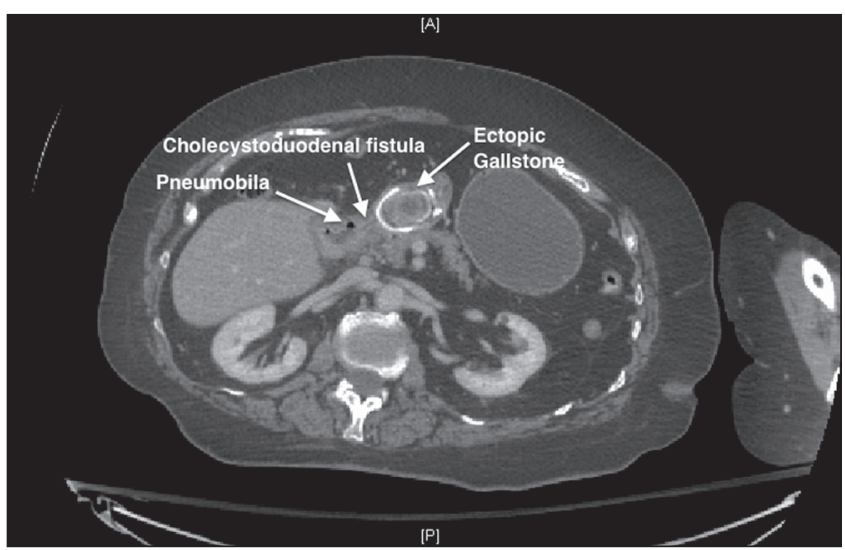

Figure 2) Computed tomography scan. Gallstone in the duodenum, cholecystoduodenal fistula and pneumobilia

Division of Gastroenterology, McMaster University, Hamilton, Ontario

Corrrespondence: Dr Harith Baharith, McMaster University, Division of Gastroenterology, 1280 Main Street West, Hamilton,

Ontario L8N 325. Telephone 289-700-2244, fax 905-648-1906, e-mail harith.baharith@medportal.ca

Received for publication November 10, 2014. Accepted December 5, 2014 


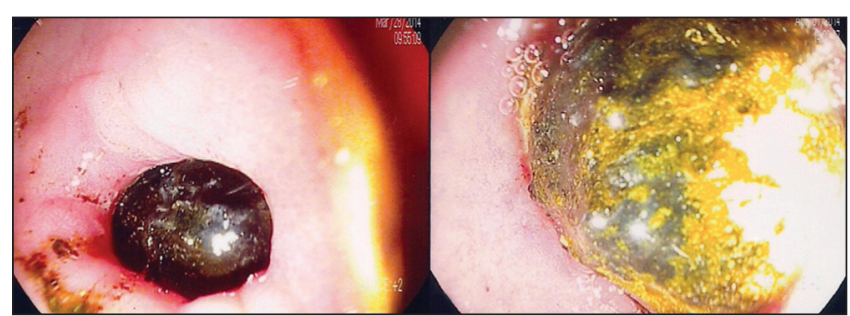

Figure 3) Endoscopy showing gallstone impacted in the duodenum

electrohydraulic lithotripsy, intracorporeal laser lithotripsy or combinations thereof, endoscopic treatment has a success rate of only $9 \%$ (9). If endoscopy is unsuccessful, patients undergo surgery for stone extraction. The most commonly performed surgical procedures are enterolithotomy or gastrostomy with or without cholecystectomy, and fistula repair (5). Postoperative mortality rates in the early 2000s were as high as $30 \%$; however, due to earlier diagnoses made possible by

\section{REFERENCES}

1. Bouveret L. Stenose du pylore adhérent à la vesicule. Rev Med (Paris) 1896;16:1-16.

2. Cappell MS, Davis M. Characterization of Bouveret's syndrome: A comprehensive review of 128 cases. Am J Gastroenterol 2006;101:2139-46.

3. Clavien PA, Richon J, Burgan S, Rohner A. Gallstone ileus. Br J Surg 1990;77:737-42.

4. Langhorst J, Schumacher B, Deselaers T, Neuhaus H. Successful endoscopic therapy of a gastric outlet obstruction due to a gallstone with intracorporeal laser lithotripsy: A case of Bouveret's syndrome. Gastrointest Endosc 2000;51:209-13.

5. Koulaouzidis A, Moschos J. Bouveret's syndrome. Narrative review. Ann Hepatol 2007;6:89-91.

6. Lassandro F, Romano S, Ragozzino A, et al. Role of helical CT in diagnosis of gallstone ileus and related conditions. AJR 2005;185:1159-65.

7. Pickhardt PJ, Bhalla S, Balfe DM. Acquired gastrointestinal fistulas: Classification, etiologies, and imaging evaluation. Radiology 2002;224:9-23. endoscopy and the advent of more minimally invasive techniques, the mortality rate has fallen to $12 \%(9,10)$. There are multiple case reports describing postoperative complications including death $(2,11,12)$.

\section{CONCLUSION}

The patient described in our case was an elderly woman with multiple comorbidities who belonged to a high-risk group. The patient's diagnostic imaging confirmed Rigler's triad. She underwent three unsuccessful therapeutic endoscopic attempts to retrieve an impacted stone - an approach with a reported success rate of only $9 \%$. The patient deteriorated rapidly during her hospital stay, which necessitated palliative management because the surgical approach was considered to be high risk. Our region has no electrohydraulic or intracorporeal laser lithotripsy facilities, which may have been a helpful endoscopic intervention. The patient died within four weeks of presentation, which reaffirms that Bouveret syndrome can cause significant morbidity and mortality.

8. Keller M, Epp C, Meyenberger C, et al. Unspecified abdominal symptoms and pneumobilia: A rare case of gastrointestinal obstruction. Case Rep Gastroenterol 2014;8:216-20.

9. Lowe AS, Stephenson S, Kay CL, May J. Duodenal obstruction by gallstones (Bouveret's syndrome): A review of the literature. Endoscopy 2005;37:82-7.

10. Halabi W, Kang CY, Ketana N, et al. Surgery for gallstone ileus: A nationwide comparison of trends and outcomes. Ann Surg 2014;259:329-35.

11 Gajendran M, Muniraj T, Gelrud A, et al. A challenging case of gastric outlet obstruction (Bouveret's syndrome): A case report. J Med Case Rep 2011;5:497.

12. O'Neill C, Colquhoun P, Schlachta CM, Etemad-Rezai R, Jayaraman S. Gastric outlet obstruction secondary to biliary calculi: 2 cases of Bouveret syndrome. Can J Surg 2009;52:E16-8.

The Canadian Journal of Gastroenterology E Hepatology is considering a limited number of submissions for IMAGE OF THE MONTH. These are based on endoscopic, histological, radiological and/or patient images, which must be anonymous with no identifying features visible. The patient must consent to publication and the consent must be submitted with the manuscript. All manuscripts should be practical and relevant to clinical practice, and not simply a case report of an esoteric condition. The text should be brief, structured as CASE PRESENTATION and DISCUSSION, and not more than 700 words in length. A maximum of three images can be submitted and the number of references should not exceed five. The submission may be edited by our editorial team. 


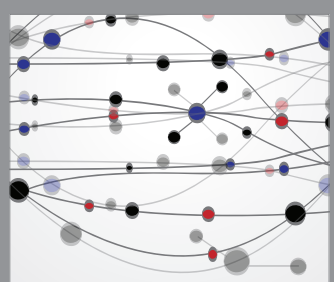

The Scientific World Journal
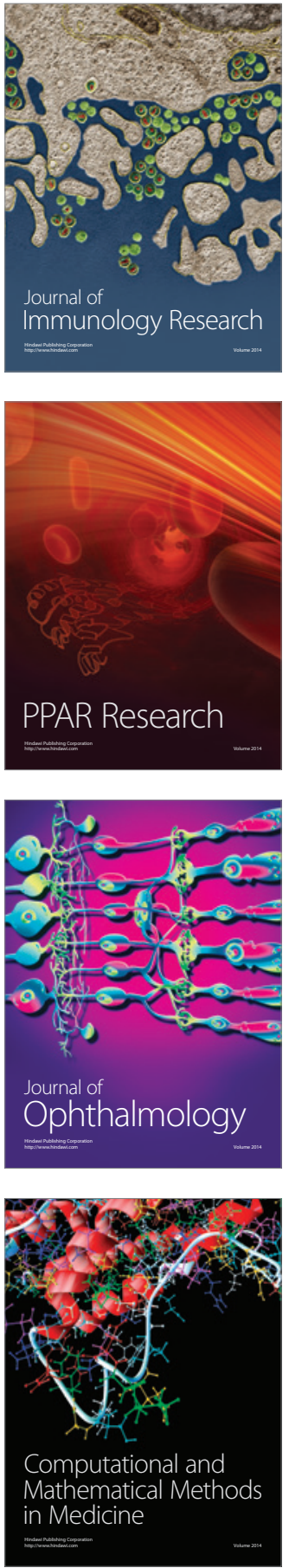

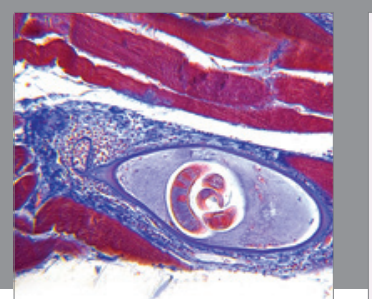

Gastroenterology Research and Practice

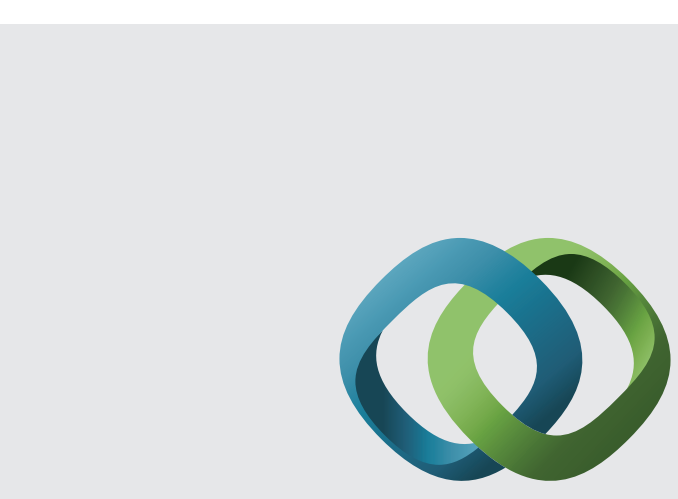

\section{Hindawi}

Submit your manuscripts at

http://www.hindawi.com
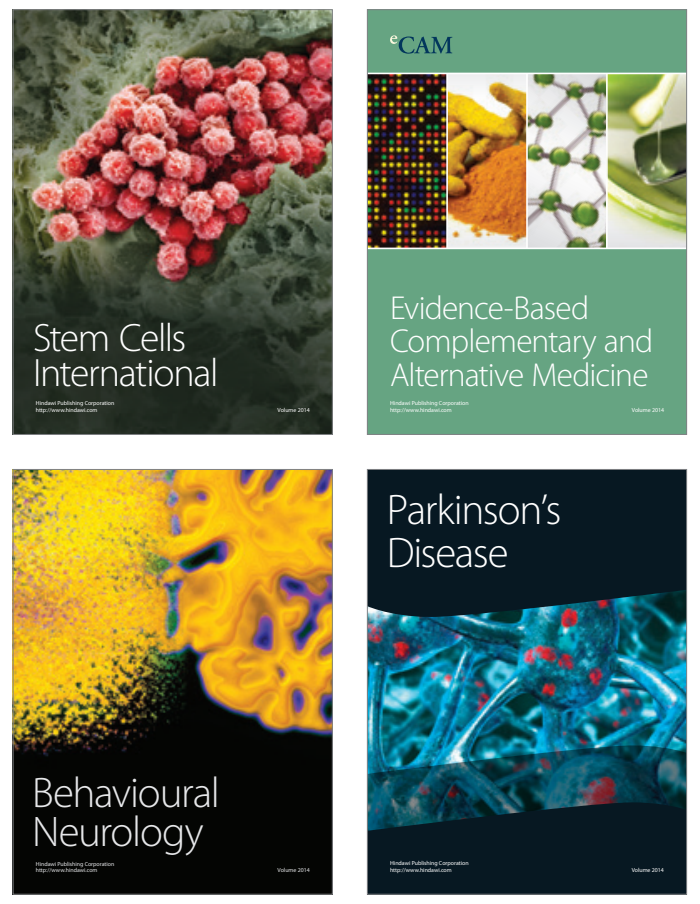
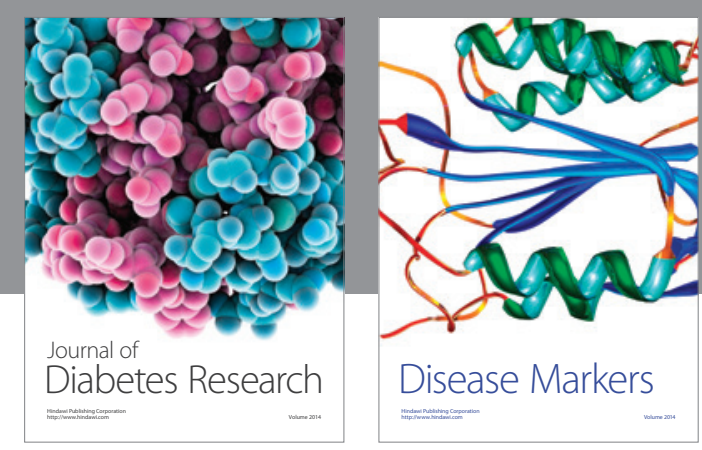

Disease Markers
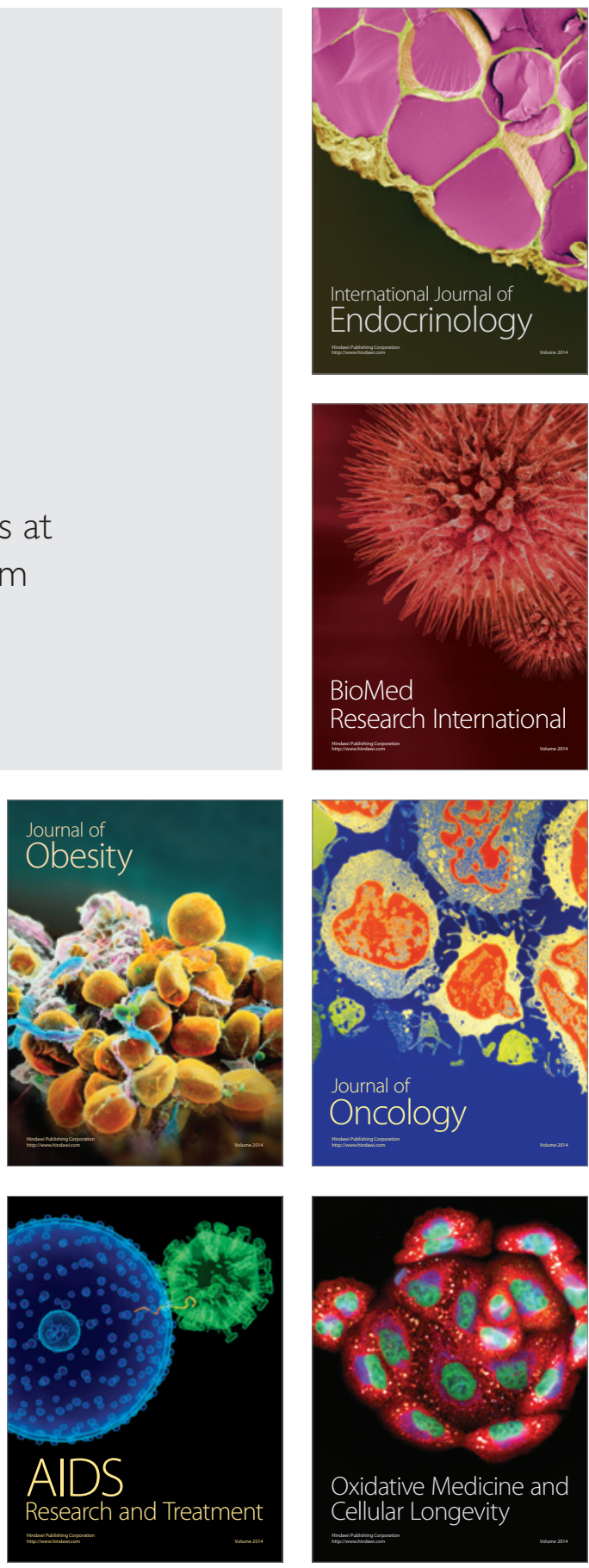